\title{
ESTIMATION OF INSTANTANEOUS EVAPOTRANSPIRATION USING REMOTE SENSING BASED ENERGY BALANCE TECHNIQUE OVER PARTS OF NORTH INDIA
}

\author{
Triparna Sett ${ }^{1, *}$, Bhaskar Ramchandra Nikam ${ }^{2}$, Subrata Nandy ${ }^{3}$, Abhishek Danodia $^{4}$, Rajarshi Bhattacharjee ${ }^{5}$, Vikas $^{2}$ \\ Dugesar $^{6}$ \\ ${ }^{1}$ M. Tech, Forestry and Ecology Department, IIRS, Dehradun, India - triparna35@gmail.com \\ ${ }^{2}$ Water Resource Department, IIRS, Dehradun, India \\ ${ }^{3}$ Forestry and Ecology Department, IIRS, Dehradun, India \\ ${ }^{4}$ Agricultural and Soils Department, IIRS, Dehradun, India \\ ${ }^{5}$ M. Tech, Geoscience Department, Indian Institute of Remote Sensing, ISRO, Dehradun, India \\ ${ }^{6} \mathrm{PhD}$ Scholar, Department of Geography, Institute of Science, Banaras Hindu University, Varanasi, India
}

\section{Commission V, SS: Natural Resources Management}

KEY WORDS: Evapotranspiration, Energy Balance Approach, Remote Sensing, Sensible heat flux

\begin{abstract}
:
Evapotranspiration (ET) is an essential element of the hydrological cycle and plays a significant role in regional and global climate through the hydrological circulation. Estimation and monitoring of actual crop evapotranspiration (ET) or consumptive water use over large-area holds the key for better water management and regional drought preparedness. In the present study, the remote sensing based energy balance (RS-EB) approach has been used to estimate the spatial variation of instantaneous evapotranspiration (ET inst). The (ETinst) is evaluated as the residual value after computing net radiation, soil heat flux and sensible heat flux using multispectral remote sensing data from Landsat-8 for the post-monsoon and summer season of 2016-2017 over the parts of North India. Cloud free temporal remote sensing data of October 12, 2016; November, 13, 2016; March 05, 2017 and May 24, 2017 were used as primary data for this study. The study showed that normalized difference vegetation index and LST are closely related and serve as a proxy for qualitative representation of (ET $\left.T_{\text {inst }}\right)$.
\end{abstract}

\section{INTRODUCTION}

Evapotranspiration (ET) is a key element in hydrological processes and termed as the second most important water balance component after precipitation. Therefore, at any given time the amount of water available in different sources and its distribution is affected by the variations in evapotranspiration (Eiji Maeda, et al., 2011). Evapotranspiration is a collective term that describes the loss of water from the Earth's surface to the atmosphere through evaporation and transpiration (Jetse et al., 2014). Evaporation is the movement of water to the air from sources (i.e. soil, canopy interception, and waterbodies) whereas, Transpiration is the movement of water within a plant and the subsequent loss of water as vapor through stomata to the atmosphere (McMohan, et al., 2013). It is the connecting link between energy and water cycle.

Evapotranspiration is plausibly the most difficult component of hydrological cycle to determine due to its simultaneous interactions between components of the land-vegetation-atmosphere system, especially in arid and semi-arid areas (Jovanovic and Israel 2004).
The land surface and atmospheric interactions are very critical for the understanding and accurate estimation of variations in spatial and temporal distribution of evapotranspiration (Mu et al., 2007). Decreasing availability of water resources in the view of impacts of climate change, human consumption of water at a rapid pace, calls for batter and improved methods to conserve and sustain water resource at both local and regional scale (Melesse et al., 2006). However, due to the involvement of a large number of controlling factors (i.e. climate, plant biophysics, soil properties, and topography) and heterogeneous landscape, it is very difficult to quantify water cycle accurately (Mu et al., 2007). Many researchers working on the characterization of the various aspects of water resources have emphasized on the importance of evapotranspiration. It accounts for the larger portion of the water losses in the water budget, it is important to quantify evapotranspiration to understand the hydrological cycle and for sustainable water resource management (Ershadi et al., 2013).

A lot of evapotranspiration estimation methods based upon weather and climatic variability measurement at fixed meteorological stations were developed (Sumner and Jacobs 2005). The widely used method of this category include the Penman-Monteith,

\footnotetext{
${ }^{*}$ Corresponding Author
} 
Priestley-Taylor (Alexandris et al., 2008; Kalma et al., 2008; Sumner and Jacobs 2005, Priestley and Taylor 1972), Thornthwaite (Maeda et al., 2011; Thornthwaite 2007), the Turc (Federer 1996; McMahon et al., 2013) and the Hargreaves-Samani (Hargreaves et al., 1985; Lu et al., 2005). For the better understanding of water lose and subsequent management of water resources evenly distributed network of meteorological stations are prerequisite. Meteorological station-based methods lack spatial representation due to their intermittent distribution (Maeda et al., 2011).

The advent of remote sensing based estimation of land cover, surface temperature $\left(\mathrm{T}_{\mathrm{s}}\right)$, reflectance, vegetation indices (VI), emissivity, and surface albedo leads to the development of evapotranspiration estimation algorithms using surface energy balance (SEB) approach (Su 2002; Bastiaanssen et al., 2005; Allen et al., 2007). Remote sensing is perceived as the most feasible tool for the study of spatial distribution of regional evapotranspiration (Wild et al., 2005). The remote sensing based SEB techniques estimate evapotranspiration as a "residual" of the land surface energy balance process. Widely used models include the Surface Energy Balance System (SEBS) (Su 2002), the Surface Energy Balance Algorithm for Land (SEBAL) (Bastiaanssen et al., 1998) and the Mapping Evapotranspiration at High Resolution with Internalized Calibration (METRIC) model (Allen et al., 2007). The SEBS model has been widely used due to its applicability at all spatial scales (i.e. local to regional), it is freely available and it has been validated in several studies ( $\mathrm{Su}$ 2007). The SEBS model also consists of a set of tools to determine surface bio-physical properties (i.e. albedo, emissivity, temperature, vegetation coverage), which are derived from satellite spectral reflectance and radiance (Su et al., 1999). It also has an extended model for determining roughness length for heat transfer; and a new formulation for deriving evaporative fraction on the basis of energy balance at limiting cases (Su 2002), as compared to other energy balance models.

The remote sensing fundamental of evapotranspiration retrieval is to obtain the latent heat flux (i.e., $\lambda_{\mathrm{ET}}$ ) as a residual of the SEB budget by solving the main components of the SEB equation that includes the sensible heat flux $(\mathrm{H})$ and ground heat flux $(\mathrm{G})$. Most of these remote sensing based evapotranspiration estimation models use remotely sensed data of surface radiation, temperature, and vegetation properties, which can be retrieved from multispectral sensors from visible \& infrared spectrum (VIS) to thermal infrared (TIR) bands.

The objective of this study was to estimate instantaneous evapotranspiration (ETinst) using the surface energy balance (SEB) model and Landsat-8 data for the 2016-2017 period over the parts of North India.

\section{STUDY AREA AND DATA USED}

The study area of the present study comprises five districts of western Uttar Pradesh (Meerut, Ghaziabad, Gautambudhnagar, Bagpath, Muzaffarnagar) and state of Delhi and its surrounding regions as shown in Figure 1. The study area lies between $28.38^{\circ}$
$\mathrm{N}$ to $29.72^{\circ} \mathrm{N}$ latitudes and from $76.85^{\circ} \mathrm{E}$ to $78.24^{\circ} \mathrm{E}$ longitudes. The main focus of study is on Delhi and its surrounding areas.

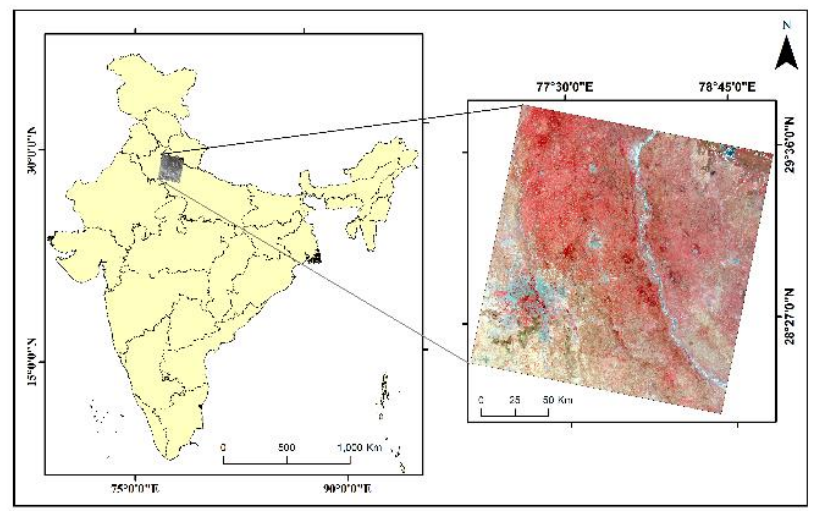

Figure 1. Location Map of Study Area

According to Koppen climatic classification, Delhi shows and overlapping kind of climate between monsoons influenced humid subtropical and semi-arid. Here, the variation between summer and winter in precipitation and temperature is quite high and significant. Temperature ranges between $45^{0}$ in summer to near freezing in winter.

\section{Data Used:}

The present study focuses only on remote sensing based estimation of evapotranspiration; hence, Landsat 8 OLI (Operational Land Imager) and TIRS (Thermal Infrared Sensor) datasets for the winter session of year 2016-17 have been utilized in the study. In the present study, four cloud free Landsat 8 images were downloaded from USGS website (https://earthexplorer.usgs.gov/). These data are covering from the October 2016 to May 2017 (12/10/2016, $13 / 11 / 2016,05 / 03 / 2017$, and 24/05/2017). The ground observed data from evapotranspiration measurement observatory equipped with Large Aperture Scintillometer (LAS), four component radiometer, ground heat flux sensor and other micor-met. Instruments was used for validation of the remote sensing based evapotranspiration results.

\section{METHODOLOGY}

To estimate the $\mathrm{ET}_{\text {inst }}$ using Landsat- 8 OLI and TIRS data the surface energy balance approach has been employed in the present study. The parameters required for solving surface energy balance process were derived using Landsat 8 data as given below:

\section{Parameterization of model}

Remote sensing based energy approach is used to estimate instantaneous evaporative fraction $(\Lambda)$ using surface reflectance and land surface temperature (LST). Since, satellite images represent only the information of overpass time, SEB technique is properly implemented to gain information on $\mathrm{ET}_{\text {inst }}$ flux for the 
imaging time. The 'residual' of the surface energy balance equation solved for each pixel of the image as

$$
\lambda E T=R n-G-H
$$

Where, $\quad \lambda \mathrm{ET}=$ latent heat flux $\left(\mathrm{Wm}^{-2}\right)$

$\mathrm{Rn}=$ net radiation flux $\left(\mathrm{Wm}^{-2}\right)$

$\mathrm{H}=$ sensible heat flux $\left(\mathrm{Wm}^{-2}\right)$

$\mathrm{G}=$ soil surface heat flux $\left(\mathrm{Wm}^{-2}\right)$

The Normalized Differential Vegetation Index (NDVI) (Van De Griend and Owe 1993) and surface albedo is generated using visible and infrared bands of OLI. Surface albedo $(\alpha)$ is computed by correcting the total $\alpha_{\text {toa }}$ of all bands for atmospheric transmissivity where $\alpha_{\text {path-radiance }}$ is average of incoming solar radiation across all bands for. Bastiaanssen et al. (2000) proposed value of $\alpha_{\text {path-radiance }}$ as 0.03 for general applications. The LST is computed using single and split window algorithms given by Nikam et al. (2016). The surface emissivity $\left(\varepsilon_{0}\right)$ is computed using NDVI (Van De Griend and Owe 1993; Nikam et al. 2016).

The net radiation flux used in the Eq. 1 is defined as the subtraction of all outgoing radiant fluxes from the all incoming radiant fluxes. So, the surface radiation balance equation is computed as:

$\mathrm{R}_{\mathrm{n}}=(1-\alpha) \times \mathrm{R}_{\mathrm{S} \downarrow}+\mathrm{R}_{\mathrm{L} \downarrow}-\mathrm{R}_{\mathrm{L} \uparrow}-\left(1-\varepsilon_{0}\right) \times \mathrm{R}_{\mathrm{L} \downarrow}$

Where, $\quad \mathrm{Rs}_{\downarrow}=$ incoming shortwave radiation $\left(\mathrm{Wm}^{-2}\right)$;

$\mathrm{R}_{\mathrm{L} \downarrow}=$ incoming longwave radiation $\left(\mathrm{Wm}^{-2}\right)$

$\mathrm{R}_{\mathrm{L} \uparrow}=$ outgoing longwave radiation $\left(\mathrm{Wm}^{-2}\right)$

$\varepsilon_{0}=$ surface thermal emissivity (dimensionless)

$\alpha=$ surface albedo (dimensionless).

Detailed procedure for calculation of these parameters using remote sensing data can be referred from Bastiaanssen et al. (2000) and Allen et al. (2007).

The soil heat flux $(G)$ which is the smallest component of this energy balance system, is defined as the amount of thermal energy that moves through an area of a soil and for vegetation also in per unit time. How fast the temperature can be changed in day time is depended on the capacity of soil conductance. The soil heat flux is estimated by using the relationship between LST, NDVI, surface reflectance proposed by Bastiaanssen et al. (2000) as:

$\frac{\mathrm{G}}{\mathrm{R}_{\mathrm{n}}}=\frac{T_{s}}{\alpha}\left(0.0038 \alpha+0.0074 \alpha^{2}\right)(1-0.98 \mathrm{NDVI})^{4}$

Where, $\mathrm{G}=$ soil heat flux $\left(\mathrm{Wm}^{-2}\right)$

$\mathrm{Rn}=$ net shortwave radiation $\left(\mathrm{Wm}^{-2}\right)$

$\mathrm{T}_{\mathrm{S}}=$ land surface temperature $\left({ }^{\circ} \mathrm{C}\right)$

$\alpha=$ surface albedo (dimensionless)

NDVI $=$ normalized difference vegetation index.

Then, the most complex part of this energy balance system is the calculation of sensible heat flux $(\mathrm{H})$. There will a change in rate of heat loss by conduction and convection process. To calculate $\mathrm{H}$ a scatterplot between surface albedo and LST is generated. The LST values are calculated regarding to lowest to highest albedo values. Next the dry edge and cold edge is derived in the scatterplot of LST and surface albedo. For wet pixel it was assumed that $\mathrm{H}$ will be equal to 0 and for dry pixel the $\lambda \mathrm{E}$ will be 0 (Danodia et al., 2017).
The evaporative fraction is the ratio of latent heat flux and the total heat leaving the earth's surface it can be represented as:

$$
\Lambda=\frac{T_{h}-T_{S}}{T_{h}-T_{\lambda E}}
$$

Where, $\Lambda=$ evaporative fraction;

$\mathrm{T}_{\mathrm{h}}=$ surface temperature of dry pixel with minimum latent heat flux $(\lambda \mathrm{E}=0)$

$\mathrm{T}_{\lambda \mathrm{E}}=$ surface temperature of wet pixel with minimum sensible heat $(\mathrm{H}=0)$.

So, it can be re-written as:

$$
\Lambda=\frac{\lambda E}{\lambda E+H}=\frac{\lambda E}{R n-G}
$$

After calculation of evaporative fraction, the sensible heat flux can calculated as:

$$
H=(1-\Lambda)(R n-G)
$$

Where, $\mathrm{H}=$ Sensible heat flux $\left(\mathrm{Wm}^{-2}\right)$

$\Lambda=$ evaporative fraction (dimensionless)

$\mathrm{Rn}=$ net radiation $\left(\mathrm{Wm}^{-2}\right)$

$\mathrm{G}=$ soil heat flux $\left(\mathrm{Wm}^{-2}\right)$

Then the latent heat flux which is defined as the rate of latent heat loss from the surface due to evaporation, is calculated as:

$$
\lambda E T=R n-G-H
$$

Where, $\lambda E T=$ the instantaneous value for the time of the satellite overpass $\left(\mathrm{Wm}^{-2}\right)$

$\mathrm{Rn}=$ net radiation $\left(\mathrm{Wm}^{-2}\right)$

$\mathrm{G}=$ soil heat flux $\left(\mathrm{Wm}^{-2}\right)$

$\mathrm{H}=$ sensible heat flux $\left(\mathrm{Wm}^{-2}\right)$

Finally, the instantaneous evaporation is calculated as:

$$
E T_{\text {inst }}=\left(\frac{\lambda E T}{\lambda}\right) \times 3600
$$

Where, $\mathrm{ET}_{\text {inst }}=$ instantaneous evapotranspiration $(\mathrm{mm} / \mathrm{hr})$

$\lambda=$ the latent heat of vaporization $(3600$ is for conversion from seconds to hour).

\section{RESULTS \& DISCUSSION}

Due to landscape heterogeneity, the surface energy balance shows large variations. The surface energy balance components are regulated by various environmental and meteorological parameters. Therefore, the monthly as well as seasonally variation can be observed in various aspects. The series of LST, NDVI, surface albedo, net radiation, soil heat flux, sensible heat flux, latent heat flux, evaporative fraction and lastly the instantaneous evapotranspiration are generated in this present study.

Overall, the range of LST varies between $14.27^{\circ} \mathrm{C}$ to $45.32^{\circ} \mathrm{C}$ with the highest LST being observed on $24^{\text {th }}$ May 2017. The Delhi NCR region which is situated at the south-west corner of the study area is showing higher LST on all four dates as compared to its surrounding extent (Figure 2) which establishes the concept of urban heat island because of anthropogenic activities. 

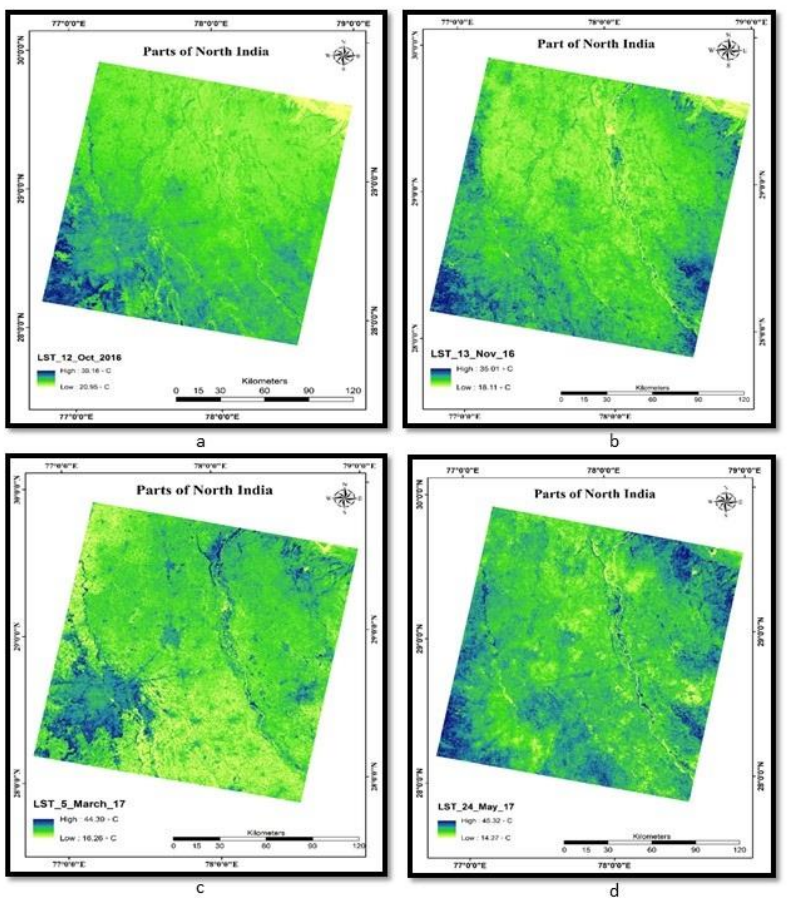

Figure 2. Land Surface Temperature a) 12/10/2016; b) $13 / 11 / 2016$; c) $05 / 03 / 2017$; d) $24 / 05 / 2017$
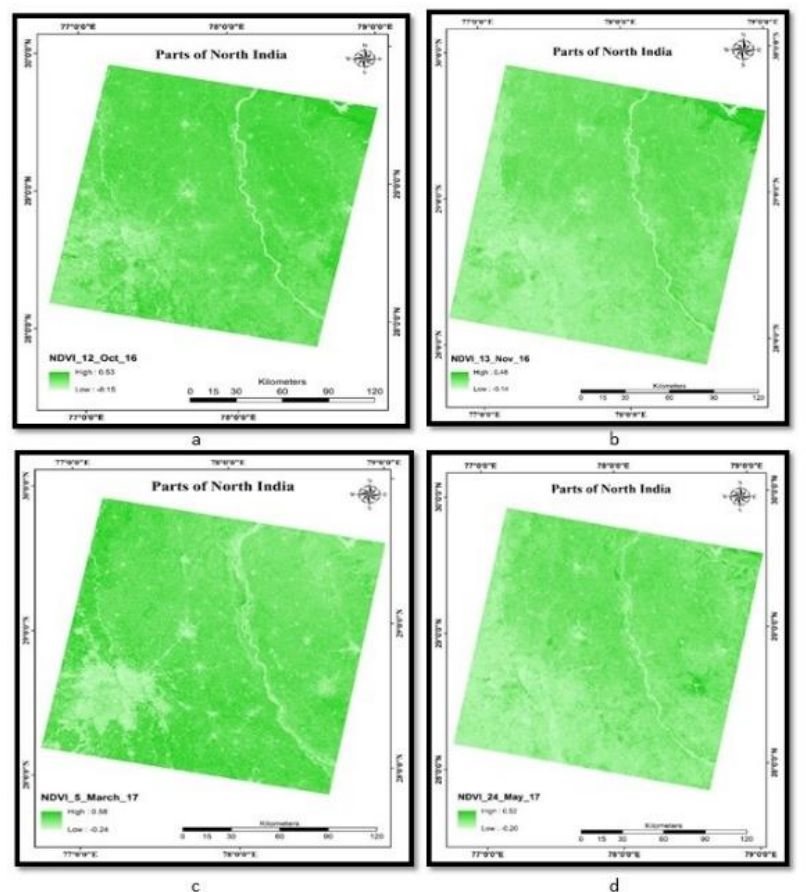

Figure 3. Normalized Difference Vegetation Index a) $12 / 10 / 2016$; b) $13 / 11 / 2016$; c) $05 / 03 / 2017$; d) $24 / 05 / 2017$

The temporal variation in NDVI within the study area is shown in Figure 3. It has been observed that NDVI and LST are inversely proportional to each other. For the given time period, NDVI value ranges between $-0.2\left(24^{\text {th }}\right.$ May, 2007) and $0.58\left(5^{\text {th }}\right.$ March, 2017) while the LST value ranges between $16.26^{\circ} \mathrm{C}\left(5^{\text {th }}\right.$ March, 2017) and $45.32^{\circ} \mathrm{C}\left(24^{\text {th }}\right.$ May, 2007).

Subtle variation in surface albedo $(\alpha)$ (Figure 4$)$ is quite obvious in the scene in respect to the changing time frame with the values ranging between 0.05 to 0.85 . The highest and lowest albedo was recorded on $5^{\text {th }}$ March, 2017 and $13^{\text {th }}$ November, 2016 respectively which highlights an inverse relationship between albedo and LST as materials having low surface albedo tend to have high absorptivity subsequently leading to an upsurge in surface temperature.
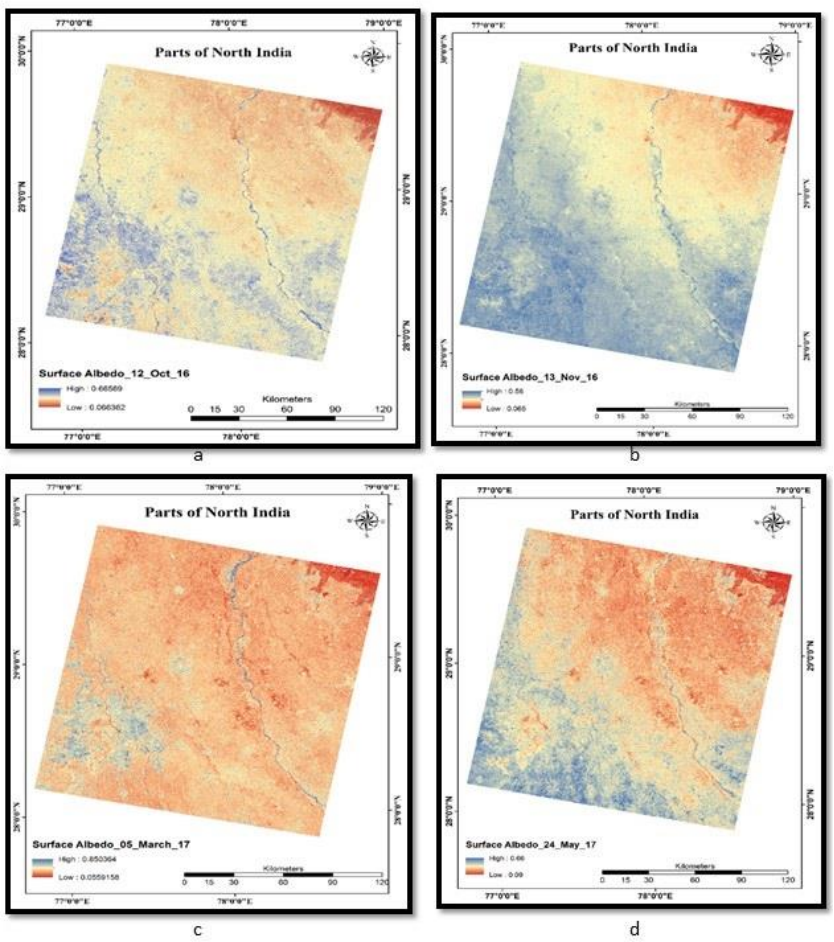

Figure 4. Surface Albedo a) 12/10/2016; b) 13/11/2016; c) $05 / 03 / 2017$; d) $24 / 05 / 2017$

Net radiation $R_{n}$ (Figure 5) represents the actual radiant energy available in the surface. It is estimated based on incoming short and long wave radiation, outgoing long wave radiation and surface albedo. (Bastiaanssen et al., 2000; Sobrino et al., 2005). 24 $4^{\text {th }}$ May, 2017 marks the day with the highest $R_{n}$ values ranging between $350.04 \mathrm{~W} / \mathrm{m}^{2}$ to $722.82 \mathrm{~W} / \mathrm{m}^{2}$ while the lowest range of net radiation was recorded on $13^{\text {th }}$ November, 2016 varying between $207.59 \mathrm{~W} / \mathrm{m}^{2}$ to $588.51 \mathrm{~W} / \mathrm{m}^{2}$. This implies low net radiation in respect to the urban scenario as compared to the forests because of the low surface absorptivity of the urban fabrics.

Soil heat flux G (Figure 6) also shows substantial amount of variation within the considered time span. The computed soil heat flux registers its peak values ranging between $41.51 \mathrm{~W} / \mathrm{m}^{2}$ to $107.23 \mathrm{~W} / \mathrm{m}^{2}$ on $24^{\text {th }}$ May, 2017. Meanwhile, the lowest range of values spanning between $41.22 \mathrm{~W} / \mathrm{m}^{2}$ to $73.38 \mathrm{~W} / \mathrm{m}^{2}$ has been recorded on $16^{\text {th }}$ November, 2016. As already known soil heat flux refers to the heat flux absorbed by the different soil layers or concrete structures in case of urban belts. However, as the thermal 
capacity of buildings is much higher than that of soil, as such the urban based soil heat flux dominates the heat flux values prevalent over the forest areas.
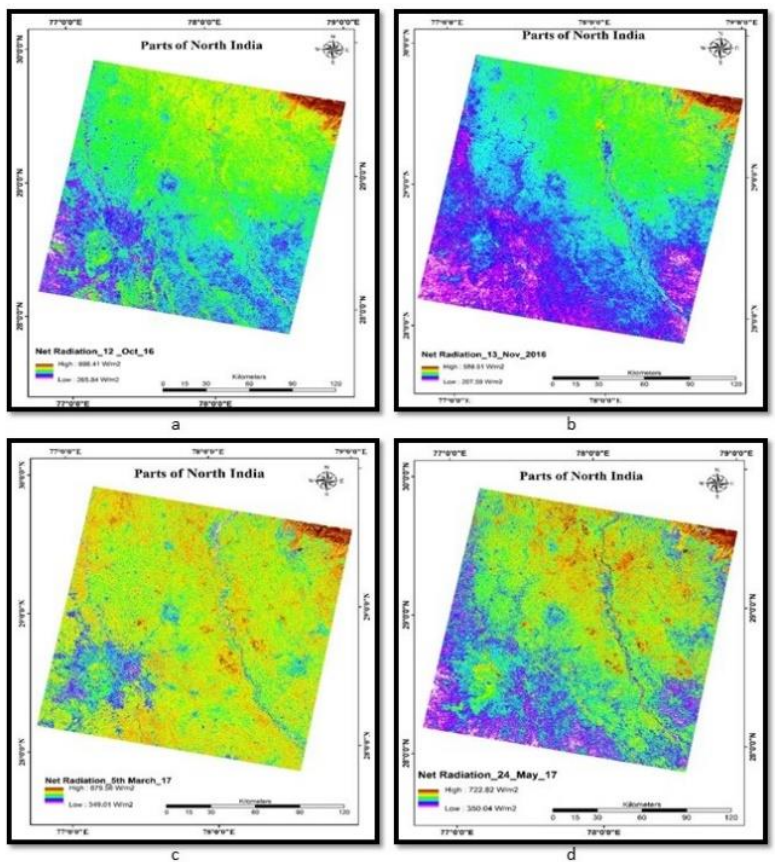

Figure 5. Net Radiation a) 12/10/2016; b) 13/11/2016; c) $05 / 03 / 2017$; d) 24/05/2017
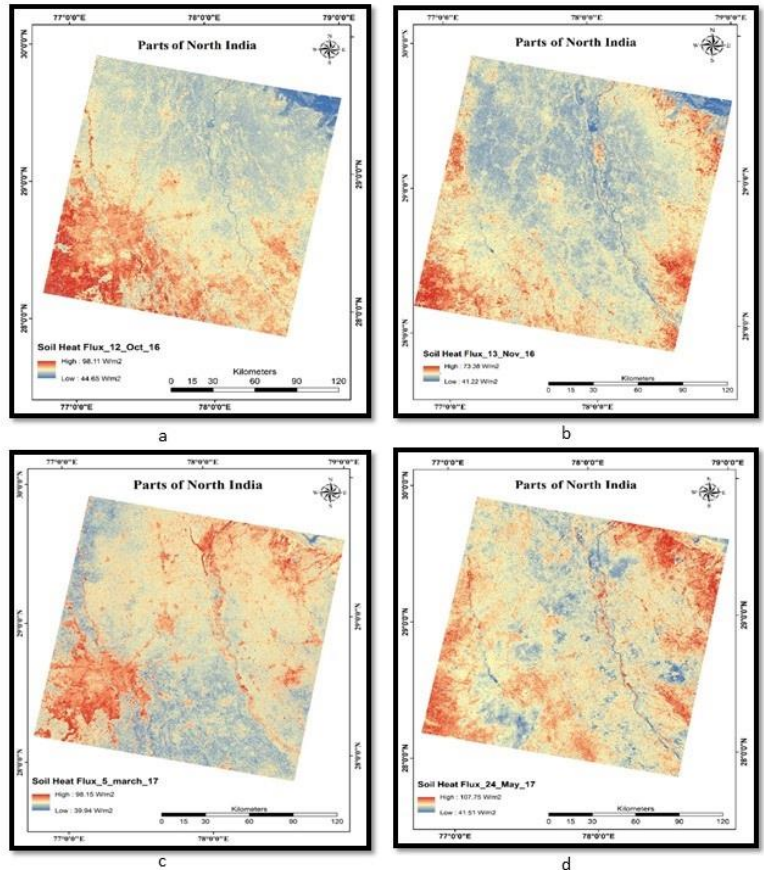

Figure 6. Soil Heat Flux a) 12/10/2016; b) 13/11/2016; c) $05 / 03 / 2017$; d) $24 / 05 / 2017$

Like the aforementioned parameters, the variation in sensible heat flux $\mathrm{H}$ (Figure 7) is also quite apparent both spatially and temporally. The range of $\mathrm{H}$ is limited between $0-375.39 \mathrm{~W} / \mathrm{m}^{2}$ as computed for $13^{\text {th }}$ November, 2016 while $5^{\text {th }}$ March, 2017 registers a crest with $\mathrm{H}$ varying between $0-504.55 \mathrm{~W} / \mathrm{m}^{2}$. The sensible heat flux has an increasing trend over the urban extent because evapotranspiration lowers the air temperature over the forest and agricultural patches. The lack of moisture within the urban fabrics leads to a drop in latent heat transfer which in the urban fabrics eventually leads to a surge in soil heat flux as well as sensitive heat flux.
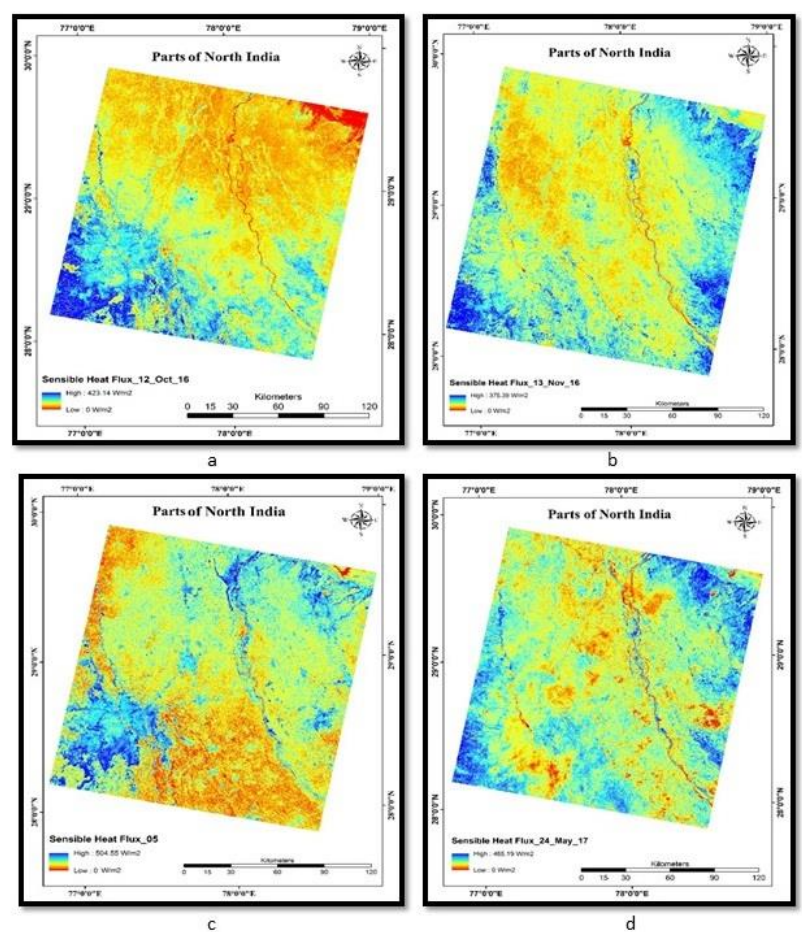

Figure 7. Sensible Heat Flux a) 12/10/2016; b) 13/11/2016; c) $05 / 03 / 2017$; d) 24/05/2017

Latent heat flux $\lambda_{\mathrm{ET}}$ is the major contributor in the energy balance equation $\lambda_{\mathrm{ET}}$ hits its crest $\left(624.21 \mathrm{~W} / \mathrm{m}^{2}\right)$ and trough $\left(466.14 \mathrm{~W} / \mathrm{m}^{2}\right)$ on $12^{\text {th }}$ October, 2016 and $13^{\text {th }}$ November, 2016 respectively as evident from Figure 8 . In spatial context, $\lambda_{\mathrm{ET}}$ is perceptibly higher over the forest belt because of the high moisture content prevalent over the area leading to high rate of evapotranspiration which eventually contributes to the hike in latent heat flux. On the other hand, the lack of moisture over the urban landscape doesn't facilitate the phase change which adversely affects the latent heat flux.

Figure 9 demonstrates the spatio-temporal variation instantaneous evapotranspiration $\left(\mathrm{ET}_{\text {inst }}\right)$ over the study area. There exists a linear relationship between $\lambda_{\mathrm{ET}}$ and $\mathrm{ET}_{\text {inst }}$ with both being function of evapotranspiration. The $\mathrm{ET}_{\text {inst }}$ rate becomes evidently high on $5^{\text {th }}$ March, 2017 which is around $0.57 \mathrm{~mm} / \mathrm{hr}$ while $24^{\text {th }}$ May, 2017 sees a drastic fall in $\mathrm{ET}_{\text {inst }}$ at $0.37 \mathrm{~mm} / \mathrm{hr}$. As obvious, the rates are quite high over the forest areas because of the high evapotranspiration rates predominating the vegetative patches. 

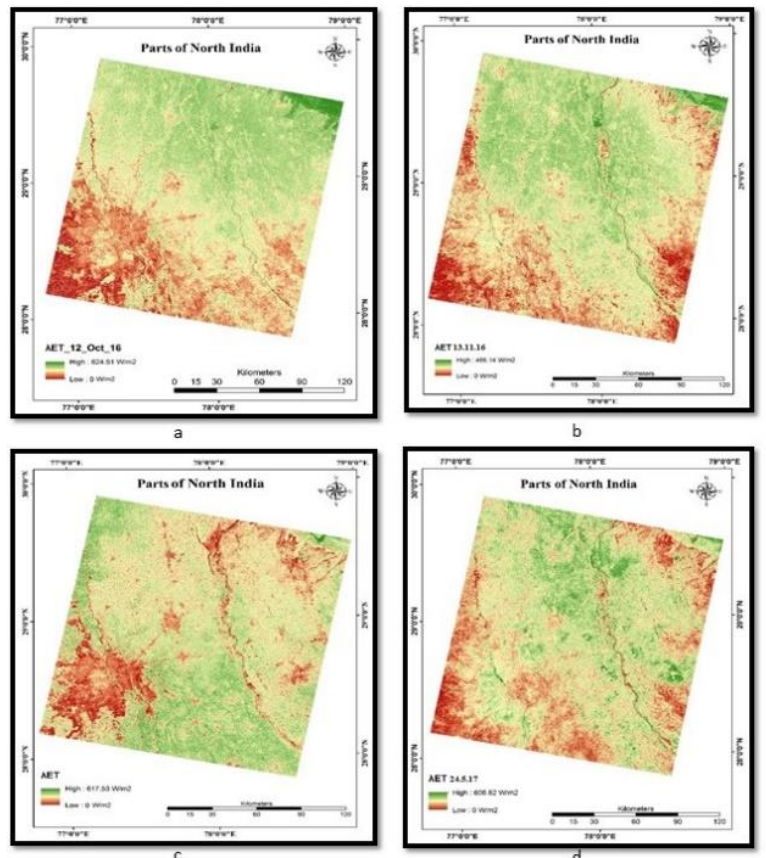

Figure 8. Latent Heat Flux a) 12/10/2016; b) 13/11/2016; c) $05 / 03 / 2017$; d) 24/05/2017
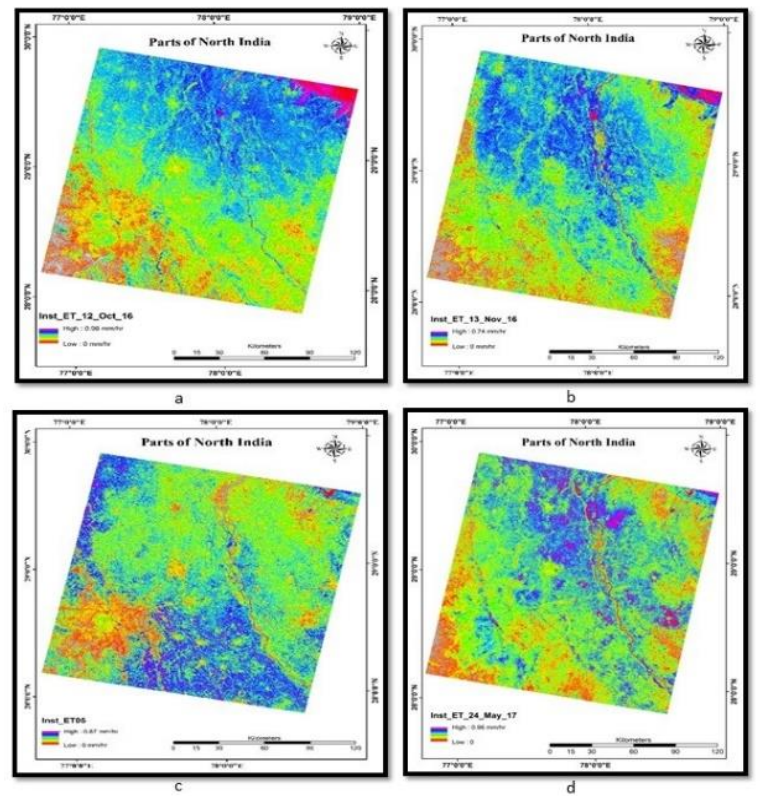

Figure 9. Instantaneous Evapotranspiration a) 12/10/2016; b) $13 / 11 / 2016$; c) $05 / 03 / 2017$; d) $24 / 05 / 2017$

The process evapotranspiration establishes the link between water and energy balance and describe the land surface coupling with the atmosphere. In RS-BE methods, only the transfer of sensible heat flux $(\mathrm{H})$ is estimated using observed (RS) data and latent heat flux $(\lambda \mathrm{ET})$ is termed as residual energy. The radiative fluxes (shortwave radiation and longwave radiation) are controlled by emissivity and temperature of surface and atmosphere. Besides turbulent fluxes (latent heat flux and sensible heat flux) are controlled by temperature and wind speed. Segregation of latent heat and sensible heat fluxes largely controls surface temperature and induced by heterogeneous land cover. From this study it is observed that, on the $12^{\text {th }}$ October 2016, net radiation is very high in forest area than urbanized area because old growth forest absorbs more heat energy than second growth forest. The areas which showing the higher albedo on $5^{\text {th }}$ March 2017 are the area which absorbs less radiation. The surface albedo is decreased with the wetness of the surface. The soil heat flux on $24^{\text {th }}$ May 2017 is high in urban area and low in forest area. The greater the soil heat flux greater will be the conduction of heat in the soil. The agricultural land which has wet soil has high thermal conductivity than dry soil. The soil heat flux varies from pre monsoon, monsoon and post monsoon season. The diurnal variation of soil heat flux is also influenced by incoming solar radiation intensity. Another component is latent heat flux which also depends on these variables. Especially for the urban landscape more net radiation is stored and convection of heat occurs which warms the urban fabric as well as the surrounding atmosphere also. On $12^{\text {th }}$ October 2016 this variation is occurred which results in less availability of latent heat. Basically, this study shows the predominance of latent heat over sensible heat. The storage of heat in vegetation biomass is negligible compared with storage of heat in the soil. For forest area there is a high evaporation rate which leads to high latent heat loss and forest area also has low surface temperature which reflects low albedo that leads to low sensible heat loss. However, for urban area the latent heat flux is lower than sensible heat flux due to urban climate depends more on landscape heterogeneity pattern. It is also observed that high latent heat is driven by cooling of land surface as well as low latent heat is driven by heating of land surface (LE $\uparrow$ when $\mathrm{H} \downarrow$ and $\mathrm{LE} \downarrow$ when $\mathrm{H} \uparrow$ respectively). Besides the vegetated area with sparse vegetation cover represent low soil moisture and less humidity. In this area for same intensity solar radiation higher albedo can be seen, but due to high surface temperature and lower rate of evaporation which results in higher sensible heat loss and lower latent heat loss. Evaporative fraction which is constant during daytime is also playing significant role in the energy balance. Evaporative fraction measurement is potential factor to estimate surface characteristics from temperature and energy flux measurements. As the evapotranspiration rate is much higher in the forest area than urban and agricultural land so $\mathrm{ET}_{\text {inst }}$ is also higher in forest area than agricultural and urban area which is evident from results of all the dates, especially on $5^{\text {th }}$ March 2017.

\section{CONCLUSION}

Accurate estimation of evapotranspiration is very crucial for various hydrological and agricultural applications. Thus, good understanding of its spatial-temporal variability is indispensable for the improved representation across a variety of modelling and resource management. Remote Sensing based energy balance approach is employed in the present study, to estimate instantaneous evapotranspiration in the parts of north India mostly covering western Uttar Pradesh, Delhi-NCR and surrounding region. All the inputs parameters for the RS-BE method are derived from Landsat 8 OLI and TIRS datasets of winter and summer sessions of 2016-17. 
It was observed that the land surface temperature (LST) of the study area reaches its subtle maxima on 24/05/2017; this is due to high emissivity of dry soil during the summer season. The average value of LST of maximum and minimum ranges from $14.27^{\circ} \mathrm{C}$ to $45.32^{\circ} \mathrm{C}$ in the south west corner of this image where the most urbanized area of Delhi NCR region is situated.

Sensible heat flux $(\mathrm{H})$ in the study area also shows the similar trend as of LST. The NDVI and surface albedo $(\alpha)$ in that region varies from -0.24 to 0.58 on $05 / 03 / 2017$ and highest albedo ranges from 0.09 to 0.66 on $24 / 05 / 2017$. Net radiation $(\mathrm{Rn})$ is seasonally varying high to low, where $\mathrm{G} / \mathrm{Rn}$ ratios are 0.07 to 0.27 for 05/03/2017, 0.09-0.29 for12/10/2016, 0.07-0.21 for 13/11/2016 and $0.09-0.31$ for $24 / 05 / 2017$. The highest $\mathrm{G} / \mathrm{Rn}$ ratio is shown in the month of March, 2017. Average latent heat $\left(\lambda_{\mathrm{ET}}\right)$ flux in that region and average instantaneous evapotranspiration values in that region during the season varies from $578.75\left(\mathrm{~W} / \mathrm{m}^{2}\right)$ for with over average instantaneous evapotranspiration values $0.563 \mathrm{~mm} / \mathrm{hr}$ for $12 / 10 / 2016 ; 375 \mathrm{~mm} / \mathrm{hr}$ for $13 / 11 / 2016 ; 0.571 \mathrm{~mm} / \mathrm{hr}$ for $05 / 03 / 2017$ and $0.373 \mathrm{~mm} / \mathrm{hr}$ for $24 / 05 / 2017$, respectively.

The spatial and temporal variation in evapotranspiration is very well mapped using this technique. The vegetated area appears to have highest evapotranspiration rate and area under urban and barren land shows lowest evapotranspiration rate.

\section{REFERENCES}

Alexandris, S, R Stricevic, and S Petkovic. 2008. 'Comparative Analysis of Reference Evapotranspiration from the Surface of Rainfed Grass in Central Serbia , Calculated by Six Empirical Methods against the Penman-Monteith Formula', 17-28.

Allen, Richard G, Masahiro Tasumi, Anthony Morse, Ricardo Trezza, James L Wright, Wim Bastiaanssen, William Kramber, Ignacio Lorite, and Clarence W Robison. 2007. 'Satellite-Based Energy Balance for Mapping Evapotranspiration with Internalized Calibration, METRIC - Applications', no. August: 395-406.

Bastiaanssen, W.G.M., M. Menenti, R.A. Feddes, and A.A.M. Holtslag. 1998. 'A Remote Sensing Surface Energy Balance Algorithm for Land (SEBAL). 1. Formulation'. Journal of Hydrology 212-213 (December). Elsevier: 198-212. doi:10.1016/S0022-1694(98)00253-4

Bastiaanssen, W G M. 2000. 'SEBAL-Based Sensible and Latent Heat Fluxes in the Irrigated Gediz Basin , Turkey’ 229: 87-100.

Bastiaanssen, W G M, E J M Noordman, H Pelgrum, G Davids, B P Thoreson, and R G Allen. 2005. 'SEBAL Model with Remotely Sensed Data to Improve Water-Resources Management under Actual Field Conditions', no. February: 85-93.

Danodia, A., Patel, N. R., Chol, C. W., Nikam, B. R. and Sehgal, V. K. 2017. Application of S-SEBI model to map crop evapotranspiration using Landsat-8 OLI data over Western Uttar Pradesh region of India. Geocarto International, doi: 10.1080/10106049.2017.1374473

Eiji Maeda, Eduardo, David A Wiberg, and Petri K E Pellikka. 2011. 'Estimating Reference Evapotranspiration Using Remote Sensing and Empirical Models in a Region with Limited Ground Data Availability in Kenya'. Applied Geography 31 (1). Elsevier
Ltd: 251-58. doi:10.1016/j.apgeog.2010.05.011.

Ershadi, A, M F Mccabe, J P Evans, and J P Walker. 2013. 'Remote Sensing of Environment Effects of Spatial Aggregation on the Multi-Scale Estimation of Evapotranspiration'. Remote Sensing of Environment 131. Elsevier Inc.: 51-62. doi:10.1016/j.rse.2012.12.007.

Federer, C A. 1996. 'Intercomparison of Methods for Calculating Potential Evaporation in Regional and Global Water Balance Models' 32 (7): 2315-21.

George H. Hargreaves, and Zohrab A. Samani. 1985. 'Reference Crop Evapotranspiration from Temperature'. Applied Engineering in Agriculture 1 (2): 96-99. doi:10.13031/2013.26773.

Griend, A. A. Van De, and M. Owe. 1993. 'On the Relationship between Thermal Emissivity and the Normalized Difference Vegetation Index for Natural Surfaces'. International Journal of Remote Sensing 14 (6): 1119-31. doi:10.1080/01431169308904400.

Jetse D. Kalma $Æ$ Tim R. McVicar Æ Matthew. 2008. 'Estimating Land Surface Evaporation: A Review of Methods Using Remotely Sensed Surface Temperature Data', 421-69. doi:10.1007/s10712008-9037-z.

Jovanovic, Nebo, and Sumaya Israel. 2004. 'Critical Review of Methods for the Estimation of Actual Evapotranspiration in Hydrological Models'.

Liou, Yuei An, and Sanjib Kumar Kar. 2014. 'Evapotranspiration Estimation with Remote Sensing and Various Surface Energy Balance Algorithms-a Review'. Energies 7 (5): 2821-49. doi:10.3390/en7052821.

Lu, Jianbiao, Ge Sun, Steven G Mcnulty, and Devendra M Amatya. 2005. 'A Comparison of Six Potential Evapotranspiration Methods for Regional Use in The Southeastern United States 1' 29414: 62133.

Melesse, Assefa M, Jason Oberg, Vijay Nangia, Ofer Beeri, and David Baumgartner. 2006. 'Spatiotemporal Dynamics of Evapotranspiration at the Glacial Ridge Prairie Restoration in Northwestern Minnesota' 1464 (December 2005): 1451-64. doi:10.1002/hyp.5960.

$\mathrm{Mu}$, Qiaozhen, Faith Ann Heinsch, Maosheng Zhao, and Steven W Running. 2007. 'Development of a Global Evapotranspiration Algorithm Based on MODIS and Global Meteorology Data'. doi:10.1016/j.rse.2006.07.007.

Nikam, B. R., Furkat Ibragimov, Arpit Chouksey, Vaibhav Garg, and S. P. Aggarwal. 2016. 'Retrieval of Land Surface Temperature from Landsat 8 TIRS for the Command Area of Mula Irrigation Project'. Environmental Earth Sciences 75 (16). Springer Berlin Heidelberg. doi:10.1007/s12665-016-5952-3.

Priestley, C H B, Taylor, R.J., 1972. 'On the Assessment of Surface Heat Flux and Evaporation Using Large-Scale Parameters'. Commonwealth Scientific and Industrial Research Organization, (February), 81-92.

Penman, H L, and Proc R Soc Lond A. 1948. 'Natural Evaporation from Open Water, Bare Soil and Grass Article Cited In':, 120-45. 
doi:10.1098/rspa.1948.0037.

Sobrino, José A., Juan C. Jiménez-Muñoz, and Leonardo Paolini. 2004. 'Land Surface Temperature Retrieval from LANDSAT TM 5'. Remote Sensing of Environment 90 (4): 434-40. doi:10.1016/j.rse.2004.02.003.

Su, Z. 2002. 'The Surface Energy Balance System (SEBS) for Estimation of Turbulent Heat Fluxes'. Hydrology and Earth System Sciences 6 (1): 85-100. doi:10.5194/hess-6-85-2002.

Su, Z. 2007. 'Surface Energy Balance System for Estimation of Turbulent Heat Fluxes and Evapotranspiration'. Lecture Notes, no. September. doi:10.5194/hess-6-85-2002.

Su, Z, H Pelgrum, and M Menenti. 1999. 'Aggregation Effects of Surface Heterogeneity in Land Surface Processes'. Hydrology and Earth System Sciences. doi:10.5194/hess-3-549-1999.

Sumner, David M, and Jennifer M Jacobs. 2005. 'Utility of Penman - Monteith, Priestley - Taylor, Reference Evapotranspiration, and Pan Evaporation Methods to Estimate Pasture Evapotranspiration' 308: 81-104. doi:10.1016/j.jhydrol.2004.10.023.

T. A. McMahon, M. C. Peel, L. Lowe, R. Srikanthan, and T. R. McVicar. 2013. 'Estimating Actual , Potential , Reference Crop and Pan Evaporation Using Standard Meteorological Data: A Pragmatic Synthesis', 1331-63. doi:10.5194/hess-17-1331-2013.

Thornthwaite, C. W. 2007. 'No Title'. Geographical Review 38 (1): 55-94.

Wild, Martin, Hans Gilgen, Andreas Roesch, Atsumu Ohmura, Viivi Russak, and Anatoly Tsvetkov. 2005. 'From Dimming to Brightening: Decadal Changes in Solar Radiation at Earth' $s$ Surface', no. May: 847-51.

$\mathrm{Xu}$, Dandan. 2014. 'Compare NDVI Extracted from Landsat 8 Imagery with That from Landsat 7 Imagery'. American Journal of Remote Sensing 2 (2): 10. doi:10.11648/j.ajrs.20140202.11. 